\title{
Diagnostic Accuracy of High-Resolution CT in Early Diagnosis of COVID-19 Patients with Comparison to Reverse Transcriptase-PCR
}

Usman Khan, Sana Sharif, Fareeha Khalid, Asif Rehman, Hussain Rashid

- - - - - - - - - - - - - - - - - - - - - - - - - - - ABSTRACT

Objective: To determine the accuracy of high-resolution CT (HRCT) in early diagnosis of COVID-19 in comparison to Reverse-Transcription Polymerase Chain Reaction (RT-PCR).

Study Design and Setting: This was a retrospective study, conducted in Department of Radiology, PNS Shifa Hospital, Karachi from April 2020 to June 2020.

Methodology: A total of 115 patients were included in the study who presented with symptoms. Patient's data such as demographic details, clinical presentations, RT-PCR reports and HRCT reports were collected from the record of the hospital. Data was entered and analyzed using SPSS-25.

Results: Out of 115 study participants, 98(85.2\%) were male and 17(14.8\%) were female with the average age of 50.53 $( \pm 18.64)$ years. Fever along with cough was the most common clinical presentation, presented by $91(79.1 \%)$ subjects. In comparison to RT-PCR, sensitivity of HRCT was $96.2 \%$, its specificity standing at $60 \%$ with the overall accuracy of $93.19 \%$. Moreover, mortality Rate of these symptomatic patients was $11.30 \%$ (13 out of 115). The average age of the expired patients was $67.07( \pm 11.45)$ years and the age of discharged patients was $48.31( \pm 17.92)$ years. The difference in age was statistically significant (p-value $<0.001)$.

Conclusion: Highly specific and sensitive diagnostic tests for COVID-19 have not yet been developed. High resolution CT chest has high sensitivity for early diagnosis of COVID-19, hence HRCT should be incorporated as a primary tool in assessment criteria of hospitalized patients for early diagnosis of COVID-19.

Key words: COVID-19, HRCT, PCR, Diagnostic accuracy

How to cite this Article:

Khan U, Sharif S, Khalid F, Rehman A, Rashid H. Diagnostic Accuracy of High-Resolution CT in Early Diagnosis of COVID-19 Patients with Comparison to Reverse Transcriptase-PCR. J Bahria Uni Med Dental Coll. 2021; 11(2): 50-53 DOI: https://doi.org/10.51985/GSPD1787

- - - - - - - - - - - - - - - - - - - - - - - - - - - - - - - -

This is an Open Access article distributed under the terms of the Creative Commons Attriution Non Commercial Liciense (http:// creativecommons/org/licences/by-nc/4.0) which permits unrestricted non commercial use, distribution and reproduction in any medium, provided the original work is properly cited.

- - - - - - - - - - - - - - - - - - - - - - - - -

\section{INTRODUCTION:}

Novel coronavirus has a non-segmented, single stranded and positive sense RNA genome. The size of this virus is larger than the other RNA viruses approximately $27 \mathrm{~kb}$ to $32 \mathrm{~kb}$ under electron microscope. ${ }^{1}$ Severe Acute Respiratory Syndrome Coronavirus (SARS-CoV) and Middle East

Usman Khan
Assistant Professor, Department of Radiology
I PNS SHIFA Hospital, Karachi
Sana Sharif
Senior Registrar, Department of Radiology
I ENS SHIFA Hospital, Karachi
I Fareeha Khalid
I Senior Registrar, Department of Radiology
I PNS SHIFA Hospital, Karachi
I Asif Rehman
I Assistant Professor, Department of Radiology
I PNS SHIFA Hospital, Karachi
I Hussain Rashid
I PNSStant Professor, Department of Radiology
I Received: 18-09-2020
I Accepted: 05-03-2021

Respiratory Syndrome Coronavirus (MERS-CoV) belong to the same coronaviridae family. The transmission rate of this family is high among others. Both viruses were first discovered in bats. Clinical manifestations are common in coronavirus infections with respiratory symptoms or intestinal symptoms. ${ }^{2,3}$ Cases of corona virus spread like wildfire around the globe. That's why, World Health Organization declared it as a public health emergency of international concern (PHEIC). But on $26^{\text {th }}$ February 2020, Pakistan's Federal Health Ministry confirmed the first case in the country. It was the time when 113 countries around the globe were already witnessing the wave of the pandemic. Pakistan is located between two major corona virus infected countries, Iran and China. It was an unrealistic approach to consider Pakistan immune from such disease of high virulence because these microbes do not respect borders. ${ }^{4}$

Primarily COVID-19 was diagnosed as viral pneumonia. Clinical presentation in prodromal phase was dry cough, fever, nasal congestion, and body aches. Some patients even not had these symptoms. Gastrointestinal manifestation in the form of diarrhea was also presented in a few patients. Diagnostic capacity was not enough to do mass screening of travelers and their close contacts through RT-PCR as kits were not available in sufficient quantity. Flight operation 
was halted and pilgrims coming from Iran were quarantined as a measure to prevent its spread. ${ }^{3,4,5}$

Reverse-Transcription Polymerase Chain Reaction (RTPCR) is used to diagnose viral RNA. Samples are taken from nasopharyngeal swab, oropharyngeal swab or bronchial lavage. High incidence rate of the disease increases the burden of RT-PCR tests on labs. This is considered as a gold stranded test for diagnosis but it is failed to detect virus early due to high false negative rate in initial phase. ${ }^{6,7}$ In contrast, high resolution CT chest scan is a one breath hold, quicker way to diagnose early COVID-19 patients. It has been observed that patients having clinical symptoms were PCR negative while they had typical findings on their chest HRCT. Findings related to COVID-19 were Ground Glass Opacities (GGOs), consolidations, interlobular septal thickening and mixed patterns (fig $1 \& 2$ ). Early detection of virus might help to prevent more aggressive response of COVID-19. ${ }^{7,8}$

Literature suggests that HRCT has more sensitivity than RT-PCR in early detection of virus. ${ }^{9,10}$ HRCT is suggested for every patient to confirm early definitive diagnosis. According to World Health Organization guidelines, CT chest and radiograph were main diagnostic tools during prevalence of SARS. ${ }^{15}$ National guidelines of Pakistan published by National institute of Health (NIH) on $2^{\text {nd }}$ April 2020 indicated that there is role of chest radiograph in diagnosis among COVID-19 suspected patients having symptoms from mild to critical severity. ${ }^{20}$ There is a debate on the use of HRCT as early diagnostic tool. Therefore this study was conducted to determine the diagnostic accuracy of high resolution CT (HRCT) in comparison to Reverse Transcriptase-Polymerase Chain Reaction (RT-PCR).

\section{METHODOLOGY:}

In this study, 115 corona symptomatic/suspected patients were advised for getting HRCT scan done. It was a retrospective study and all data collected from the hospital's record. Subjects registered for HRCT in Radiology Department of PNS Shifa Hospital, Karachi and having prodromal symptoms of Corona virus were included in this study. Duration of study was three months from $1^{\text {st }}$ April to $30^{\text {th }}$ June 2020. Patients with the bronchial asthma, COPD, ILD, Tuberculosis and heart failure were excluded from study. Convenient sampling technique was used. Our study approved by the hospital ethical review committee with approval number ERC/2020/RADIO/29. Clinical presentation at the time of admission, and RT-PCR results also noted from the hospital record.

The RT-PCR tests performed on oropharyngeal swabs. The test kits recommended by Chinese Center for Disease Control and Prevention used to test. Negative control and internal control regularly performed with each batch. Laboratory technicians, instruments, and kits were same for all tests.
The CT Scan machine had 16 slice multi detector CT scanners. Images were taken in supine position at $1 \mathrm{~mm}$ slice thickness with $10 \mathrm{~mm}$ gap. Lung window was used to evaluate all the CT images at level of $500 \mathrm{HU}$ and width of 1500 HU. Two senior consultant radiologists, each having 12 and 15 years of experience, reviewed all the images while they were blinded to name, clinical data and laboratory findings.

Data was entered and analyzed using SPSS version 25.0. Numerical data like age was presented in the form of mean and standard deviation while categorical data like PCR and HRCT findings were presented in frequency and percentages. For numerical data comparison, independent sample $t$ test and for categorical data association, chi square test was applied considering $\mathrm{p}$-value $<0.05$ as statistically significant.

\section{RESULTS:}

In this study 115 subjects were screened for HRCT chest scan. The mean age was $50.89( \pm 18.31)$ years. Among them $17(14.8 \%)$ were females and $98(85.2 \%)$ were males. Mean ages of male and female were $50.53( \pm 18.64)$ years and $53.36( \pm 16.41)$ years, respectively.

Clinical presentation of patients was correlated with the gold stranded test Reverse Transcriptase Polymerase Chain Reaction (RT-PCR) for COVID-19. At the time of presentation, 84(80\%) subjects having fever and cough had PCR positive and 7(70\%) subjects were negative. Similarly, among the patients presented with cough $47(44.8 \%)$ were positive and $6(60 \%)$ were negative. Among the patients having shortness of breath, 44(41.9\%) were positive and $4(40 \%)$ were negative. Among the patients with complaint of body aches, 33(31.4\%) were positive and 2(20\%) were PCR negative. (table no 1)

While comparing the HRCT findings, consolidations were noted in 17(16.2\%) PCR COVID-19 positive patients. On other hand, no consolidations were documented in negative cases. Ground Glass Opacities (GGOs) were detected in $48(45.7 \%)$ positive patients while it was seen in $4(40 \%)$ negative patients as well. $29(25.2 \%)$ patients had unilateral and others had bilateral Ground Glass Opacities (GGOs). Among the PCR positive patients 82(78.1\%) had typical findings of COVID-19 on high resolution CT chest including crazy paving pattern, GGOs, interlobular septal thickening, consolidation and pleural involvement; meanwhile, 2(20\%) PCR negative patients also showed these typical findings on scan. (table no 1)

Graph: 1 Diagnostics comparison of HRCT and PCR: Among the PCR positive subjects, HRCT detected 101(96.2\%) subjects as positive (Sensitivity). Among the PCR negative subjects, HRCT detected 6(60\%) subjects (Specificity) and among the HRCT positive subjects, PCR detected 101(96.2\%) subjects as positive (Positive predictive value). Among the HRCT negative subjects, PCR detected $6(60 \%)$ subjects (Negative predictive value). (Graph no 1) 
Diagnostic Accuracy of High-Resolution CT in Early Diagnosis of COVID-19 Patients with Comparison to Reverse Transcriptase-PCR

\section{Graph: 2, Survival rate of COVID-19 Patients}

Total 15(13\%) patients presented in our hospital with clinical features suggestive of COVID-19 and PCR positive expired while the $100(87 \%)$ cases recovered from disease and were subsequently discharged. Mean age of the expired patients was $67.07( \pm 11.45)$ years and mean age of discharged patients was $48.31( \pm 17.92)$ years. The difference in age was statistically significant (p-value $<0.001$ ). (Graph No 2).

Figure 1: HRCT Axial section showing GGOs and consolidation with air bronchograms

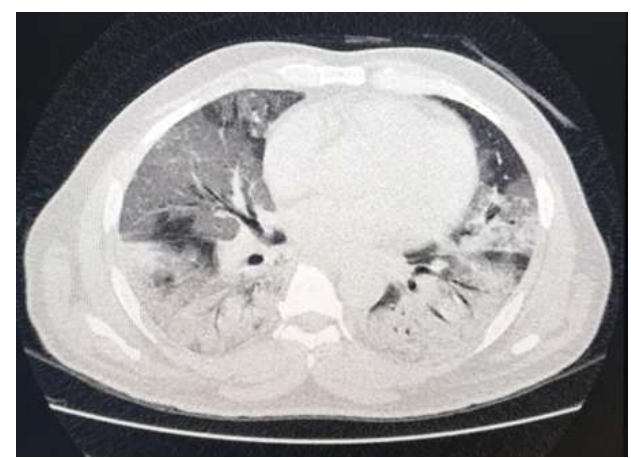

Figure 2: HRCT Axial section showing interlobular septal thickening

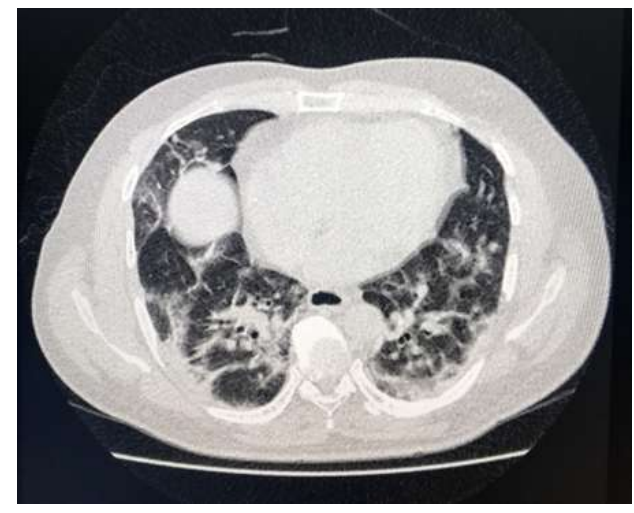

Table 1: Comparison of findings with COVID-19 PCR

\begin{tabular}{|l|l|c|c|c|}
\hline Categories & \multicolumn{1}{|c|}{ Findings } & \multicolumn{2}{|c|}{ COVID-19 PCR } & \multirow{2}{*}{ P-value } \\
\cline { 3 - 5 } & & Positive & Negative & \\
\hline \multirow{5}{*}{ Symptoms } & Fever with cough & $84(80 \%)$ & $7(70 \%)$ & 0.347 \\
\cline { 2 - 5 } & Cough & $47(44.8 \%)$ & $6(60 \%)$ & 0.276 \\
\cline { 2 - 5 } & Shortness of breath & $44(41.9 \%)$ & $4(40 \%)$ & 1.000 \\
\cline { 2 - 5 } & Body Ache & $33(31.4 \%)$ & $2(20 \%)$ & 0.510 \\
\hline \multirow{5}{*}{$\begin{array}{l}\text { HRCT } \\
\text { Findings }\end{array}$} & Positive & $101(96.2 \%)$ & $4(40 \%)$ & $<0.001 *$ \\
\cline { 2 - 5 } & Consolidation & $17(16.2 \%)$ & $0(0 \%)$ & 0.188 \\
\cline { 2 - 5 } & $\begin{array}{l}\text { Ground Glass } \\
\text { Opacity (GGO) }\end{array}$ & $48(45.7 \%)$ & $4(40 \%)$ & 1.000 \\
& $\begin{array}{l}\text { thickening with } \\
\text { crazy paving } \\
\text { appearance (Typical } \\
\text { covid) }\end{array}$ & $82(78.1 \%)$ & $2(20 \%)$ & $<0.001 *$ \\
\hline Outcome & Expired & $15(13 \%)$ & $0(0.0 \%)$ & 0.233 \\
\hline
\end{tabular}

Graph: 1 Diagnostics comparison of HRCT and PCR

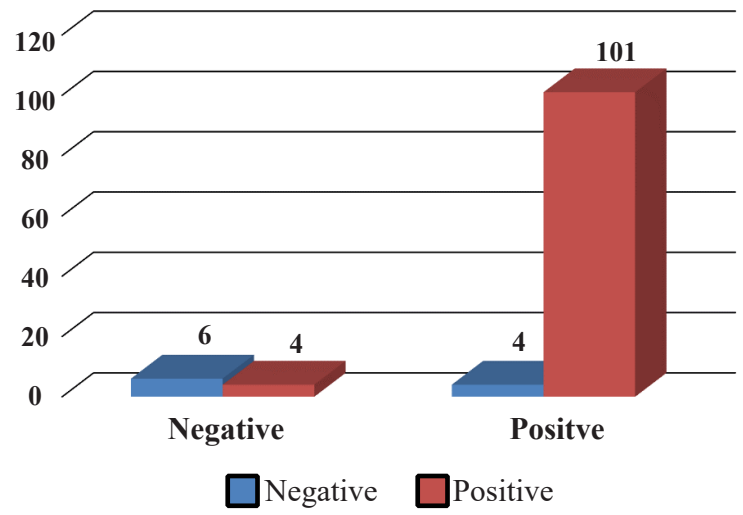

Graph 2: Survival rate of COVID-19 Patients

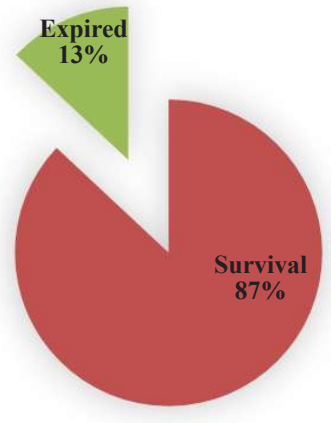

$\square$ Expired $\square$ Survived

\section{DISCUSSION:}

In our study, fever with cough was most common symptom in $91(79.13 \%)$ out of 115 patients on the day of presentation. Shortness of breath was present in $48(41.73 \%)$ patients while body aches were in 35 (34.43\%) patients. These results are consistent with other studies. ${ }^{12,13}$ Our results showed that $17(16.2 \%)$ patients had consolidations, 52 (45.2\%) had only ground glass opacities and 84 (73\%) had GGOs along with other features of COVID-19. Consolidations and GGOs were less in our study than the other ones but overall HRCT findings of COVID-19 were same as reported in other studies. It is stated that Ground Glass Opacities (GGOs) appear in early stage of disease and crazy paving, consolidation, plural involvement shows disease progression. ${ }^{14,15}$ HRCT showed $96.2 \%$ sensitivity and specificity was $60 \%$ whereas overall accuracy was 93.19 percent. Though, PCR sensitivity reported more or less $60 \% \cdot{ }^{16,17} 87 \%$ of patients completely recovered from all symptoms along with $13 \%$ mortality of in-hospital patients. ${ }^{18}$ Rivera-Izquierdo $\mathrm{M}$ et al. study showed more mortality rate than our study. ${ }^{19}$

Corona virus is a capsulated single stranded enveloped RNA virus causing COVID-19. Transmission is from human to human through droplets. Early identification is necessary 
to reduce the morbidity and mortality. ${ }^{11}$ RT-PCR is a gold standard diagnostic investigation for corona virus. Sampling through swab from oropharynx and nasopharynx is advised to do but technique is dependent on expertise of laboratory technician. On the other hand, the gold standard nucleic acid test has high failure rate in detecting virus in very early stage. $^{6}$

Limitations of this study are that this is a single center with limited number of patient's data. We could not trace disease progression or resolution. More studies are required on this topic. National guidelines of Pakistan should be revised on the basis of evidence to include HRCT to early diagnose COVID-19. ${ }^{20}$

\section{CONCLUSION:}

High Resolution Computed Tomography has shown good specificity, sensitivity and accuracy. HRCT along with etiology and symptoms is a reliable tool for early diagnosis of COVID-19 patients.

Authors Contribution:

Isman Khan: Selection of topic and introduction

I Sana Sharif: Methodology and literature review

I Fareeha Khalid: Abstract and data collection

Asif Rehman: Data Analysis

Hussain Rashid: Discussion --------

\section{REFERENCES:}

1. Lai MM, Cavanagh D. The molecular biology of coronaviruses. InAdvances in virus research 1997 Jan 1 (Vol. 48, pp. 1-100). Academic Press.

2. Cui J, Li F, Shi ZL. Origin and evolution of pathogenic coronaviruses. Nature Reviews Microbiology. 2019 ;17(3):18192.

3. Li W, Shi Z, Yu M, Ren W, Smith C, Epstein JH, Wang H, Crameri G, Hu Z, Zhang H, Zhang J. Bats are natural reservoirs of SARS-like coronaviruses. Science. 2005;310(5748):6769.

4. Saqlain M, Munir MM, Ahmed A, Tahir AH, Kamran S. Is Pakistan prepared to tackle the coronavirus epidemic?. Drugs \& Therapy Perspectives. 2020:1-2.

5. Wu J, Wu X, Zeng W, Guo D, Fang Z, Chen L, Huang H, Li C. Chest $\mathrm{CT}$ findings in patients with coronavirus disease 2019 and its relationship with clinical features. Investigative radiology. 2020;55(5):257.

6. Diao K, Han P, Pang T, Li Y, Yang Z. HRCT imaging features in representative imported cases of 2019 novel coronavirus pneumonia. Precision Clinical Medicine. 2020;3(1):9-13.

7. Tahamtan A, Ardebili A. Real-time RT-PCR in COVID-19 detection: issues affecting the results.
8. Shi H, Han X, Jiang N, Cao Y, Alwalid O, Gu J, Fan Y, Zheng C. Radiological findings from 81 patients with COVID-19 pneumonia in Wuhan, China: a descriptive study. The Lancet Infectious Diseases. 2020 Feb 24.

9. Ai T, Yang Z, Hou H, Zhan C, Chen C, Lv W, Tao Q, Sun Z, Xia L. Correlation of chest CT and RT-PCR testing in coronavirus disease 2019 (COVID-19) in China: a report of 1014 cases. Radiology. 2020:200642.

10. Fang Y, Zhang H, Xie J, Lin M, Ying L, Pang P, Ji W. Sensitivity of chest CT for COVID-19: comparison to RTPCR. Radiology. 2020 Feb 19:200432.

11. Schoeman D, Fielding BC. Coronavirus envelope protein: current knowledge. Virology journal. 2019;16(1):1-22.

12. Liu Y, Sun W, Li J, Chen L, Wang Y, Zhang L, Yu L. Clinical features and progression of acute respiratory distress syndrome in coronavirus disease 2019. MedRxiv. 2020 Jan 1.

13. Kakodkar P, Kaka N, Baig MN. A comprehensive literature review on the clinical presentation, and management of the pandemic coronavirus disease 2019 (COVID-19). Cureus. 2020;12(4).

14. Li B, Li X, Wang Y, Han Y, Wang Y, Wang C, Zhang G, Jin J, Jia H, Fan F, Ma W. Diagnostic value and key features of computed tomography in Coronavirus Disease 2019. Emerging Microbes \& Infections. 2020;9(1):787-93.

15. Xiong Y, Sun D, Liu Y, Fan Y, Zhao L, Li X, Zhu W. Clinical and high-resolution CT features of the COVID-19 infection: comparison of the initial and follow-up changes. Investigative radiology. 2020

16. Cao Y, Han X, Gu J, Li Y, Liu J, Alwalid O, Cui Y, Zhang X, Zheng C, Fan Y, Wu H. Prognostic Value of Baseline Clinical and HRCT Findings in 101 Patients with Severe COVID-19 in Wuhan, China.

17. Deng M, Sun W, Hu J, Mei L, Weng D, Liu B, Xu H. Radiological Features on HRCT and RT-PCR Testing for the Diagnosis of Coronavirus Disease 2019 (COVID-19) in China: A Comparative Study of 78 Cases in Pregnant Women.

18. Liu Y, Du X, Chen J, Jin Y, Peng L, Wang HH, Luo M, Chen L, Zhao Y. Neutrophil-to-lymphocyte ratio as an independent risk factor for mortality in hospitalized patients with COVID19. Journal of Infection. 2020 Apr 10.

19. Rivera-Izquierdo M, del Carmen Valero-Ubierna M, RdelAmoJL, Fernández-GarcíaMÁ, Martínez-Diz S, TaheryMahmoud A, Rodríguez-Camacho M, Gámiz-Molina AB, Barba-Gyengo N, Gámez-Baeza P, Cabrero-Rodríguez C. Sociodemographic, clinical and laboratory factors on admission associated with COVID-19 mortality in hospitalized patients: A retrospective observational study. PloS one. 2020;15(6)235107.

20. Khan AN, Din NU, Umer US. COVID-19 National Pakistan Guidelines: Radiological Society of Pakistan (RSP) Recommendations Regarding Utilisation of Chest Imaging. JPMA. The Journal of the Pakistan Medical Association. 2020;70(5):S7-10. 